\title{
The harm caused by marihuana use disorders is interrelated in some european countries to the harm caused by new psychoactive substances
}

\author{
Andrzej Brodziak* \\ Institute of Nursing, University of Applied Sciences Nysa, Poland
}

Hasin et al. draw the conclusions from their repeated surveys that "changing laws and attitudes toward marijuana" appeal for a necessity to confront "policy makers, professionals, and the public" with the increased prevalence of marijuana use disorders [1].

In many European countries, the great concern of the public health is related not only to the use of marijuana and hard drugs but also to using so called "new psychoactive substances (NPS)" [1,2]. According to current surveys $5-15 \%$ of young people in the EU countries have tried the substance at least once in their lives. Most of such people are in Ireland (16\%) and United Kingdom (10\%).

The harm caused by marihuana use disorders is interrelated to the harm caused by NPS, because - if in a country the possession and use of marijuana is illegal, many especially young people reach for these new "designer drugs".

Prevention and treatment of poisonings caused by the use of these NPS is difficult, because very often the identification of the used substance is not easy and the procedures of treatment are unknown.

An example of such difficulties may be the action taken against the mysterious wave of poisonings, reported in Poland in July 2015 [3]. The additions to the lists of illegal substances (like Schedule I) of new determined derivates are not an efficient amendments of the preventing law. The NPS are distributed often as bath salts, household chemicals or industrial chemicals, and are labeled with warnings "not for human consumption" [2]. Experiences gained from dealing with such a massive wave of poisonings incline to develop new concepts of the legislation that would prohibit selling of all sorts of "chemicals" with the "inappropriate intention" and suggestion for the possibility to use them as drugs. Justification of such accusations for "inappropriate intention of sale" would be similar to conjectural prosecution (circumstancial evidences) [4].

It seems that the changes in the law, regulating the availability of marijuana should take into account the new legislation formulated to prevent the spread of the use of NPS.

Investigations are needed to check if the introduction, in some countries or US states of legislation allowing the legal possession and even the use of marijuana for recreational purposes reduces drastically the use of NPS. The consequences of the different legislative solutions like in Netherlands, Czech Republic or Portugal should be verified [5].

\section{References}

1. Hasin DS, Saha TD, Kerridge BT, Goldstein RB, Chou SP, et al. (2015) Prevalence of Marijuana Use Disorders in the United States Between 2001-2002 and 2012-2013. JAMA Psychiatry 72: 1235-1242.[Crossref]

2. Martinotti G, Lupi M, Carlucci L, Cinosi E, Santacroce R, et al. (2015) Novel psychoactive substances: use and knowledge among adolescents and young adults in urban and rural areas. Hum Psychopharmacol 30: 295-301.[Crossref]

3. Zawilska JB, Andrzejczak D (2015) Next generation of novel psychoactive substances on the horizon - A complex problem to face. Drug Alcohol Depend 157: 1-17.[Crossref]

4. Poland steps up fight against designer drugs (2015) The Warsaw Voice. http://www warsawvoice.pl/WVpage/pages/article.php/32371/news

5. Belackova V, Maalsté N, Zabransky T, Grund JP (2015) "Should I Buy or Should I Grow?" How drug policy institutions and drug market transaction costs shape the decision to self-supply with cannabis in the Netherlands and the Czech Republic. Int $J$ Drug Policy 26: 296-310.[Crossref]
Copyright: (C2016 Brodziak A. This is an open-access article distributed under the terms of the Creative Commons Attribution License, which permits unrestricted use, distribution, and reproduction in any medium, provided the original author and source are credited.
Correspondence to: Prof. Andrzej Brodziak, M.D. Ph.D., Institute of Nursing, State Higher School of Applied Sciences, Nysa, Poland, Tel: +48605044609; 4877 4091660; Fax: 4877 4355244; E-mail: andrzejbrodziak@wp.pl

Received: January 18, 2016; Accepted: January 23, 2016; Published: January 26, 2016 